•研究报告・

\title{
基于森林碳库动态评估神农架国家级 自然保护区的保护成效
}

\author{
邓舒雨 ${ }^{1,2}$ 董向忠 ${ }^{3}$ 马明哲 ${ }^{1,2}$ 藏振华 1,4 \\ 徐文婷 ${ }^{1}$ 赵常明 1 谢宗强 ${ }^{1}$ 申国珍 ${ }^{*}$ \\ 1 (中国科学院植物研究所植被与环境变化国家重点实验室, 北京 100093) \\ 2 (中国科学院大学, 北京 100049) \\ 3 (北京丹青园林绿化有限责任公司，北京 100093) \\ 4 (北京林业大学森林资源与生态系统过程北京市重点实验室, 北京 100083)
}

\begin{abstract}
摘要：保护区是维持生物多样性和生态系统功能的最有效方式, 但其保护成效有待提升, 土地利用变化是重要影 响因素之一。本研究以神农架国家级自然保护区为对象, 基于神农架地区近 20 年的调查研究和数据积累, 通过异 速生长模型、生物量方程、抽样加权等方法, 对比分析了土地利用方式转变格局下神农架国家级自然保护区森林 生态系统地上、地下、调落物、粗木质残体、土壤有机碳 5 个碳库动态, 分析论证了 20 年间(1990-2010)神农架保 护区对森林生态系统碳库的保护成效。研究发现, 林地占神农架保护区总面积的 $92.76 \%$, 其中针叶林 $(51.85 \%$ )、 落叶阔叶林 $(35.11 \%$ )及常绿阔叶林 $(4.47 \%) 3$ 种森林类型合计占林地面积的 $98.56 \%$ 。20年间神农架保护区林地面积 增加了 $0.11 \%$, 灌木林地和耕地面积分别减少了 $8.85 \%$ 和 $6.06 \%$ 。神农架保护区 2010 年碳储量为 $24.24 \mathrm{Tg} \mathrm{C}$ (22.57-26.62 Tg C), 土壤有机碳和地上碳合计占全部碳储量的 $90.68 \%$ 。常绿阔叶林、落叶阔叶林和针叶林 3 种森林 类型碳储量占神农架保护区碳储量的 $95 \%$ 。20年间神农架保护区 5 个碳库碳储量均有所增加, 共固碳 $25.04 \mathrm{kt} \mathrm{C}$

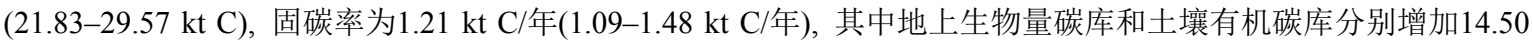

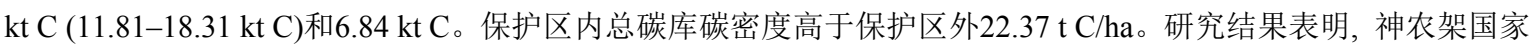
级自然保护区在保护森林固碳能力方面取得了一定的成效。
\end{abstract}

关键词：神农架国家级自然保护区; 固碳; 保护成效; 森林; 碳库

\section{Evaluating the effectiveness of Shennongjia National Nature Reserve based on the dynamics of forest carbon pools}

\author{
Shuyu Deng ${ }^{1,2}$, Xiangzhong Dong ${ }^{3}$, Mingzhe $\mathrm{Ma}^{1,2}$, Zhenhua Zang ${ }^{1,4}$, Wenting $\mathrm{Xu}^{1}$, Changming Zhao ${ }^{1}$, \\ Zongqiang Xie ${ }^{1}$, Guozhen Shen $^{1 *}$ \\ 1 State Key Laboratory of Vegetation and Environmental Change, Institute of Botany, Chinese Academy of Sciences, Bei- \\ jing 100093 \\ 2 University of Chinese Academy of Sciences, Beijing 100049 \\ 3 Beijing Danqing Gardening Co., Ltd, Beijing 100093 \\ 4 Key Laboratory for Forest Resources Ecosystem Processes of Beijing, Beijing Forestry University, Beijing 100083
}

\begin{abstract}
Nature reserves are a cornerstone of global conservation strategies. However, the effectiveness of the reserve in conserving ecosystem function such as carbon storage is poorly understood. The Shennongjia National Nature Reserve is a conservation icon and has taken exceptional efforts to protect forests. It provides a unique case to address this question. Here, we quantified the carbon storage from aboveground carbon, belowground carbon, litter, coarse woody debris, and soil organic carbon inside and outside the Shennongjia National Nature Reserve between 1990 and 2010, based on inventory data and digitized historical
\end{abstract}

收稿日期: 2017-09-05; 接受日期: 2017-12-10

基金项目: 科技基础性工作专项(2015FY1103002)和国家重点研发计划(2016YFC050330304)

* 通讯作者 Author for correspondence. E-mail: snj@ibcas.ac.cn 
land cover maps. The result showed that the woodland covered $92.76 \%$ of the reserve, most of which was coniferous forest $(51.85 \%)$, deciduous broad-leaved forest $(35.11 \%)$, and evergreen broad-leaved forest (4.47\%). Between 1990 and 2010, the area of the woodland has increased $0.11 \%$, while the area of shrubland and cropland has declined $8.85 \%$ and $6.06 \%$, respectively. The Shennongjia National Natural Reserve has accumulated $24.24 \mathrm{Tg}$ carbon (22.57-26.62 Tg C) until 2010, of which $90.68 \%$ was contributed by soil organic carbon and aboveground carbon. A total of $95 \%$ of the carbon storage in Shennongjia National Nature Reserve are contributed by evergreen broad-leaved forest, deciduous broad-leaved forest and coniferous forest. Between 1990 and 2010, the aboveground carbon pool and soil organic carbon pool has increased 14.50 kt C (11.81-18.31 kt C) and $6.84 \mathrm{kt} \mathrm{C}$, respectively. The carbon density inside the reserve is $22.37 \mathrm{t} \mathrm{C/ha}$ higher than that outside the reserve. Our results indicated that the Shennongjia National Nature Reserve is efficiently conserving forest carbon.

Key words: Shennongjia National Nature Reserve; carbon sequestration; conservation effectiveness; forest ecosystem; carbon pool

建立自然保护区是维持生物多样性和生态系 统功能稳定的最有效方式(Joppa et al, 2008; Pouzols et al, 2014)。截至2014年底, 全球已建立197,368处 自然保护区，保护区覆盖了全球陆地面积的 $15.4 \%$ (Juffe-Bignoli et al, 2014)。到目前为止, 我国已建立 2,750处自然保护区，其中国家级自然保护区446处, 占国土陆地面积的 $14.88 \%$ (http://www.zhb.gov.cn/hj zl/zghjzkgb/lnzghjzkgb/)。

保护区对生物多样性和生态系统服务功能的 保护是否达到了预期目的? 在多大程度上发挥了 保护功能? 这些是保护生物学研究中需要探讨的 问题(Andam et al, 2008; Wu et al, 2011; Hill et al, 2015; Ren et al, 2015), 目前, 有关保护区保护成效 的研究大多集中于生物多样性保护方面(Bruner et al, 2001; Rodrigues et al, 2004; Cao et al, 2015; Jenkins et al, 2015; Chen et al, 2017)。如英国的一项研 究表明, 保护区内鸟类与蝴蝶等物种的定居率是保 护区外的 4.2 倍, 257 种无脊椎动物中, $98 \%$ 的物种倾 向于在保护区内定居(Thomas et al, 2012)。美国尽管 建立了庞大的自然保护地体系, 但大部分保护地位 于美国西部，而亟需保护的物种则大多分布于美国 东南部, 保护地未能很好地保护这些物种(Jenkins et al, 2015)。我国 $81 \%$ 的植物群落都受到至少一处自 然保护区的保护(Wu et al, 2011), 保护区分别保护 了 $13.1 \%$ 的植物生境、 $17.9 \%$ 的哺乳动物栖息地和 $16.4 \%$ 的鸟类栖息地。但研究同时发现, 我国现有保 护区网络对植物、两栖和爬行动物关键栖息地的保 护成效不容乐观(Xu et al, 2017)。

保护区在保护生物多样性的同时还维持着生 态系统的众多服务功能, 固碳是其中的重要功能之
一(Ouyang et al, 2016; Xu et al, 2017)。森林是陆地 生态系统的主体, 维持着陆地地表大量的碳库(约 占全球植被碳库的 $86 \%$ 以上), 同时也维持着巨大的 土壤碳库(约占全球土壤碳库的73\%) (Tans et al, 1990; Dixon et al, 1994)。森林碳储量即便小幅度的 变动, 也可能影响整个大气 $\mathrm{CO}_{2}$ 的浓度, 进而对陆 地生态系统的分布、组成、结构和功能产生影响 (Schimel et al, 2000)。保护森林的固碳能力已成为自 然保护区的一项重要功能之一。

关于保护区保护森林固碳的成效，目前仅开展 了少量研究(Gaston et al, 2008; Willcock et al, 2016; Bowker et al, 2017; Scherer et al, 2017)。Scharlemann 等(2010)通过对全球热带森林保护区内外对比研究 发现，保护区内热带森林生物量和土壤有机碳损失 是保护区外的一半。Willcock等(2016)对非洲生物多 样性热点区域保护区建立前后森林碳动态研究发 现，保护区建立半个世纪后，保护区外森林面积减 少了 $0.7 \%$ ，而保护区内森林面积增加了 $2.7 \%$ 。同时， 由于保护区的建立，保护区内森林以 $4.8 \mathrm{Mg} \mathrm{C} / \mathrm{ha}$ 的 速率吸收固定碳, 而保护区外未受保护的森林则以 $11.9 \mathrm{Mg} \mathrm{C} / \mathrm{ha}$ 的速率丧失碳。土地利用变化是影响 森林固碳能力的重要因素之一(Joppa \& Pfaff, 2009; Houghton et al, 2012), 由土地类型转变导致的 $\mathrm{CO}_{2}$ 排放占人为 $\mathrm{CO}_{2}$ 排放的 $35 \%$ (Lambin et al, 2001; Foley et al, 2005)。

湖北神农架国家级自然保护区(以下简称神农 架保护区)保存有我国北亚热带完好的常绿落叶阔 叶混交林(谢宗强等, 2017), 孕育了丰富的生物多样 性, 形成了多样的森林生态系统, 为秦巴山地提供 了巨大的生态服务功能。20世纪70年代, 神农架曾 
进行过大规模的森林采伐, 森林生态系统结构和功 能遭到严重破坏(湖北省神农架林区地方志编纂委 员会, 1996)。1986年神农架国家级自然保护区建立, 1990 年成为联合国教科文组织人与生物圈 (MAB) 保护区，2013年成为世界地质公园，2016年被列入 世界自然遗产地名录。由此保护区内的森林开始逐 步受到严格的保护(王翠玲等, 2017)。本研究基于对 神农架地区近 20 年的调查研究和数据积累, 对比分 析了保护区内外森林生态系统的 5 个碳库动态, 以 期评估神农架保护区的建立是否对森林固碳起到 保护作用, 为探讨我国保护区的保护成效问题提供 借鉴。

\section{1 数据与方法}

\section{1 研究区域概况}

神农架保护区位于湖北省神农架林区西南部, 地理坐标为 $110^{\circ} 03^{\prime} 05^{\prime \prime}-110^{\circ} 33^{\prime} 50^{\prime \prime} \mathrm{E}, 31^{\circ} 21^{\prime} 20^{\prime \prime}-$ $31^{\circ} 36^{\prime} 20^{\prime \prime} \mathrm{N}$ 。总面积70,467 ha, 核心区面积 38,425 ha。保护区为大巴山脉东段组成的中山地貌, 呈近 东西方向延伸, 地势西南高东北低, 最高海拔神 农顶3,106.2 $\mathrm{m}$, 为华中第一峰, 最低海拔 $400 \mathrm{~m}$ (神 农架南坡)。保护区地跨中亚热带和北亚热带, 年 平均气温 $7.4^{\circ} \mathrm{C}$, 最冷月 $\left(1\right.$ 月)平均气温 $-4.3^{\circ} \mathrm{C}$, 最 热月 (7月)平均气温 $17.2^{\circ} \mathrm{C}$ 。年降水量 $800 \mathrm{~mm}-$ $2,500 \mathrm{~mm}$, 有明显的季节性。

\section{2 数据获取}

(1)森林群落调查数据。在保护区内沿海拔梯度 设置14条调查样线, 每条样线按海拔每升高 $100 \mathrm{~m}$ 设置 1 个森林样地, 或选取特殊的群落类型设置样 地。森林样地大小为 $20 \mathrm{~m} \times 30 \mathrm{~m}$ 或 $30 \mathrm{~m} \times 30 \mathrm{~m}$, 共调查 127 个。记录地名、经纬度、海拔、坡向、 坡度、土壤类型等群落环境因子, 乔木层每木调 查, 记录种名、树高、胸径和冠幅等(马明哲等, 2017)。

(2)文献数据。以“生物量”、“碳储量”、“异速生 长方程”、“生物量方程”等关键词检索国内外文献, 收集神农架地区、湖北省及附近地区对森林群落优 势种地上、地下生物量、碳储量计算方程。获取得 到保护区 42 个生物量估算方程(附录1) (罗云建等, 2015; 生态系统固碳项目技术规范编写组, 2015)。 土壤有机碳估算采用SoilGrids (www.soilgrids.org) 数据, 精度为 $250 \mathrm{~m}$ 。该数据通过机器学习方法, 依
据全球 150,000 个点的调查数据对世界不同类型土 壤碳进行模型估计(Hengl et al, 2017)。本研究基于 SoilGrids 数据, 按政府间气候变化专门委员会 (IPCC)标准计算地表 $30 \mathrm{~cm}$ 土壤有机碳含量(IPCC, $2006)$, 单位为 $\mathrm{t} \mathrm{C} / \mathrm{ha}$ 。

(3)土地利用数据。该数据采用面向对象 (objectbased)分类技术，基于神农架地区Landsat TM/ETM 数据和 $\mathrm{HJ}-1$ 卫星数据, 结合地面调查数据, 分别生 成1990年、2000年和 2010 年 $30 \mathrm{~m}$ 分辨率的土地覆盖 数据(吴炳方等, 2014; 张磊等, 2014)。

\section{3 森林生态系统碳库组成及核算}

本研究依据IPCC (2016)的碳库定义, 将神农架 保护区森林碳库分为地上碳库、地下碳库、粗木质 残体碳库、调落物碳库、土壤有机碳库 5 个碳库。

其中, 地上碳库依据地上生物量估算。地上生 物量为胸径大于 $5 \mathrm{~cm}$ 的木本植物生物量, 包括树 干、树桩、枝、树皮、籽实和叶(生态系统固碳项目 技术规范编写组, 2015)。其生物量基于样地实际调 查的优势树木的胸径、树高, 通过生物量估算方程 计算得到。地下碳库依据地下生物量估算。地下生 物量为全部树木活根生物量, 直径不足 $2 \mathrm{~mm}$ 的细 根不计在内(IPCC, 2006)。其生物量采用地上地下关 系式进行换算(附录2)(生态系统固碳项目技术规范 编写组, 2015)。粗木质残体碳库包括倒伏于地面的 树干、死根和直径 $\geq 10 \mathrm{~cm}$ 的树桩。调落物碳库即地 表枯枝落叶层。通过不同土地利用类型调落物和粗 木质残体生物量密度值或生物量碳密度值, 结合 IPCC (2006)的调落物碳库缺省值, 得到保护区相应 土地利用类型的碳值。对只有生物量而没有碳密度 值的植被类型, 采用生物量碳转换系数 0.5 进行换 算(Fang et al, 2001; Chen et al, 2013)(附录3,4)。土壤 有机碳即土壤中细根和死有机物质中的碳元素含 量。数据分析处理使用ArcGIS、R、SigmaPlot等软 件完成。

对地上和地下生物量的估算结果采用重抽样 方法生成加权平均值的置信区间。

\section{4 不同土地利用类型碳密度值}

使用ArcGIS软件将已有碳储量值的样点与土 地利用类型进行匹配。并按样地面积平方根对样地 碳储量进行抽样加权, 获取不同土地类型碳密度值 (Willcock et al, 2012)。 


\section{5 土地利用变化下碳储量变化}

通过土地利用类型面积变化计算碳储量值变 化(Lai et al, 2016):

$\Delta C_{\text {CONVERSION }}=\sum_{i}\left[\left(B_{\text {AFTERi }}-B_{\text {BEFOREi }}\right) \times \Delta A_{\text {TO_OTHERSi }}\right]$ 其中, $\triangle C_{\text {CONVERSION }}$ 为土地利用类型转变下的碳储 量变化值, $B_{A F T E R i} 、 B_{\text {BEFORE }}$ 和 $\triangle A_{\text {TO_OTHERSi }}$ 分别表 示转变后的碳储量、转变前的碳储量和转变为另一 区域的面积, $i$ 为发生转变的土地利用类型。

\section{6 保护区碳保护的有效性}

本文选取神农架保护区边界外 $5 \mathrm{~km}$ 缓冲区作 为保护区外区域(Carranza et al, 2014; Willcock et al, 2016), 计算1990-2010年20年间碳储量变化率和碳 密度变化值, 并同保护区内对比, 分析保护区的有 效性。

\section{2 结果}

\section{1 神农架保护区20年(1990-2010年)间的土地利} 用变化

统计结果表明, 在2010年, 神农架保护区林地 占保护区总面积的 $92.76 \%$, 其中针叶林 $(51.85 \%$ )、 落叶阔叶林 $(35.11 \%$ )及常绿阔叶林 $(4.47 \%) 3$ 种森林 类型合计占林地面积的 $98.56 \%$ (表1)。与 1990 年相 比，20年间，神农架保护区林地面积增加了 $0.11 \%$, 灌木林地和耕地面积分别减少了 $8.85 \%$ 和 $6.06 \%$ (表1)。

\section{2 神农架保护区主要森林类型碳库变化}

分析神农架保护区2010年各碳库碳储量发现, 神农架保护区总碳储量为24.24 Tg C (22.57-26.62 $\mathrm{Tg} \mathrm{C})$ 。其中, 地上碳库8.58 $\mathrm{Tg} \mathrm{C}(7.19-10.58 \mathrm{Tg} \mathrm{C})$,
土壤有机碳库 $13.40 \mathrm{Tg} \mathrm{C}$, 占全部碳储量的 $90.68 \%$, 地下、调落物和粗木质残体碳库分别为 $1.81 \mathrm{Tg} \mathrm{C}$ (1.53-2.19 Tg C)、0.29 Tg C和0.16 Tg C (表2)。5个 碳库中, 土壤有机碳密度最高(184.30 t C/ha), 其次 分别为地上碳密度(117.96 t C/ha (98.84-145.47 t $\mathrm{C} / \mathrm{ha})$ )、地下碳密度(24.81 t C/ha (21.09-30.13 t $\mathrm{C} / \mathrm{ha})$ )、调落物碳密度 $(3.92 \mathrm{t} \mathrm{C} / \mathrm{ha})$ 及粗木质残体碳 密度(2.22 t C/ha)(表3)。

常绿阔叶林、落叶阔叶林和针叶林 3 种森林类 型碳储量占保护区碳储量的 $95 \%$, 总碳密度分别为 383.75 t C/ha (331.92-514.00 t C/ha)、350.53 t C/ha (318.36-394.01 t C/ha) 和340.21 t C/ha (322.42$362.86 \mathrm{t} \mathrm{C} / \mathrm{ha}$ )。其中, 常绿阔叶林地上碳密度 (146.10 t C/ha (102.67-254.45 t C/ha))、地下碳密度 (30.81 t C/ha (22.41-52.71 t C/ha))、调落物碳密度 (5.09 t C/ha) 和土壤有机碳密度 $(196.97 \mathrm{t} \mathrm{C} / \mathrm{ha})$ 均最 高(图1)。

\section{3 神农架保护区碳保护的有效性}

分析发现, 1990-2010年间, 神农架保护区共固 碳25.04 kt C (21.83-29.57 kt C), 固碳率为 $1.21 \mathrm{kt} \mathrm{C/}$ 年(1.09-1.48 kt C/年)。20年间保护区 5 个碳库碳储量 均有所增加, 其中地上生物量碳库和土壤有机碳库 分别增加14.50 kt C (11.81-18.31 kt C)和6.84 kt C。保 护区内土壤有机碳密度高于保护区外 $27.11 \mathrm{t} \mathrm{C} / \mathrm{ha}$,

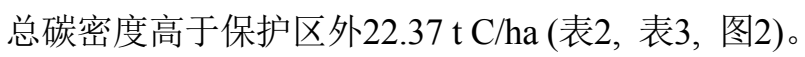

\section{3 讨论}

本研究分析了神农架保护区1990-2010年间森 林的固碳成效。研究发现, 1990-2010年间神农架保

表1 神农架国家级自然保护区土地利用格局

Table 1 Land use types and their areas in Shennongjia National Nature Reserve

\begin{tabular}{lllll}
\hline $\begin{array}{l}\text { 土地利用类型 } \\
\text { Land use type }\end{array}$ & $\begin{array}{l}\text { 1990年面积 } \\
\text { Area in 1990 (ha) }\end{array}$ & $\begin{array}{l}\text { 1990年占比 } \\
\text { Proportion in 1990 (\%) }\end{array}$ & $\begin{array}{l}\text { 2010年面积 } \\
\text { Area in 2010 (ha) }\end{array}$ & $\begin{array}{l}\text { 2010年占比 } \\
\text { Proportion in 2010 (\%) }\end{array}$ \\
\hline $\begin{array}{l}\text { 常绿阔叶林 } \\
\begin{array}{l}\text { Evergreen broad-leaved forest } \\
\text { 落叶阔叶林 }\end{array}\end{array}$ & $3,245.71$ & 4.46 & $3,249.13$ & 4.47 \\
$\begin{array}{l}\text { Deciduous broad-leaved forest } \\
\text { 针叶林 Coniferous forest }\end{array}$ & $25,448.97$ & 34.99 & $25,532.75$ & 35.11 \\
$\begin{array}{l}\text { 针阔混交林 } \\
\text { Coniferous and broad-leaved mixed forest }\end{array}$ & $37,694.08$ & 51.83 & $37,713.32$ & 51.85 \\
灌木林 Shrubland & 622.14 & 0.86 & 624.78 & 0.86 \\
耕地 Cropland & 380.97 & 0.52 & 347.26 & 0.48 \\
其他 Other & $2,056.3$ & 2.83 & $1,931.7$ & 2.66 \\
\hline
\end{tabular}




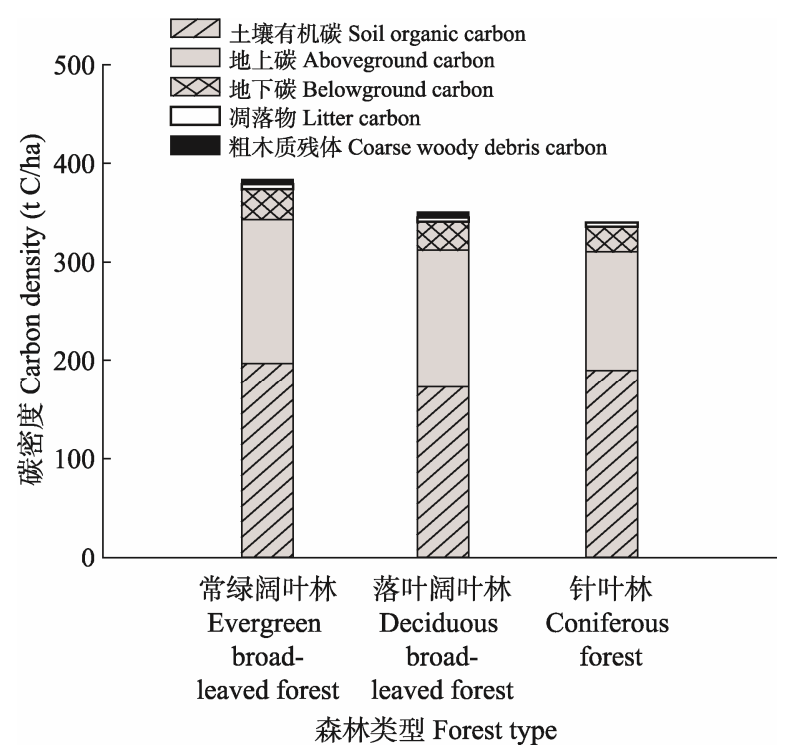

图1 神农架自然保护区主要森林类型各碳库碳密度

Fig. 1 Carbon density of different carbon pools of main forestry lands in Shennongjia National Nature Reserve

护区森林 5 个碳库碳储量均有所增加, 土壤有机碳库 碳密度及总碳库碳密度高于保护区外, 保护区固碳
取得了一定成效。

土壤碳积累和释放是陆地生态系统碳循环中 一个重要组成部分, 在全球碳循环及全球变化的研 究中具有重要的作用。全球森林碳库的 $69 \%$ 和 $31 \%$ 为土壤和植被碳库(Dixon et al, 1994)。土壤碳库是 陆地生态系统中最大的碳库，全球约有 1,400-1,500 Pg碳以有机形式储存于土壤中, 土壤碳储量是陆地 植被碳库 (500-600 Gt C) 的 2-3 倍 (Schlesinger, 1990)。我国2,473种不同土壤类型碳密度为3.5$252.6 \mathrm{t} \mathrm{C} / \mathrm{ha}$ (Xie et al, 2007)。崔鸿侠等 $(2012,2014)$ 研究发现, 神农架马尾松(Pinus massoniana)林、华 山松(Pinus armandii)林、巴山冷杉(Abies fargesii)林 的土壤碳储量分别为 $57.79 \mathrm{t} \mathrm{C} / \mathrm{ha} 、 116.07 \mathrm{t} \mathrm{C} / \mathrm{ha}$ 和 $170.62 \mathrm{t} \mathrm{C} / \mathrm{ha}$ 。本研究发现，神农架保护区土壤有机

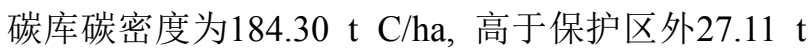
$\mathrm{C} / \mathrm{ha}$, 土壤有机碳储量占总碳储量的 $55 \%$, 是地上 碳库碳密度的1.6倍。该结果也与Willcock等(2012) 得出的土壤碳占据全部碳储量的 $60 \%$, 超过地上碳 2 倍的结论相吻合。

表2 神农架自然保护区1990-2010年间各碳库碳储量变化

Table 2 Carbon storage of different carbon pools in Shennongjia National Nature Reserve between 1990 and 2010

\begin{tabular}{|c|c|c|c|c|c|c|}
\hline & $\begin{array}{l}\text { 地上碳库 } \\
\text { Aboveground } \\
\text { carbon }\end{array}$ & $\begin{array}{l}\text { 地下碳库 } \\
\text { Belowground } \\
\text { carbon }\end{array}$ & $\begin{array}{l}\text { 调落物碳库 } \\
\text { Litter carbon }\end{array}$ & $\begin{array}{l}\text { 粗木质残体碳库 } \\
\text { Coarse woody } \\
\text { debris carbon }\end{array}$ & $\begin{array}{l}\text { 土壤有机碳㡺 } \\
\text { Soil organic } \\
\text { carbon }\end{array}$ & $\begin{array}{l}\text { 总计 } \\
\text { Total }\end{array}$ \\
\hline $1990(\operatorname{Tg~C})$ & 8.57 & 1.80 & 0.29 & 0.16 & 13.40 & 24.21 \\
\hline $2000(\operatorname{Tg~C})$ & 8.58 & 1.81 & 0.29 & 0.16 & 13.40 & 24.23 \\
\hline 2010 (Tg C) & 8.58 & 1.81 & 0.29 & 0.16 & 13.40 & 24.24 \\
\hline $\begin{array}{l}\text { 1990-2010年变化量 } \\
\triangle \mathrm{C}_{\text {storage }} 1990-2010(\mathrm{kt} \mathrm{C})(1990-2000 ; 2000-2010)\end{array}$ & $\begin{array}{l}14.50 \\
(13.93 ; 0.57)\end{array}$ & $\begin{array}{l}3.01 \\
(2.88 ; 0.13)\end{array}$ & $\begin{array}{l}0.21 \\
(0.44 ;-0.24)\end{array}$ & $\begin{array}{l}0.49 \\
(0.52 ;-0.03)\end{array}$ & $\begin{array}{l}6.84 \\
(3.97 ; 2.87)\end{array}$ & $\begin{array}{l}25.04 \\
(21.74 ; 3.30)\end{array}$ \\
\hline $\begin{array}{l}\text { 1990-2010年变化率 } \\
\text { Change rate of carbon storage during } \\
\text { 1990-2010 (\%) (1990-2000; 2000-2010) }\end{array}$ & $\begin{array}{l}0.17 \\
(0.16 ; 0.01)\end{array}$ & $\begin{array}{l}0.17 \\
(0.16 ; 0.01)\end{array}$ & $\begin{array}{l}0.07 \\
(0.16 ;-0.02)\end{array}$ & $\begin{array}{l}0.30 \\
(0.32 ;-0.02)\end{array}$ & $\begin{array}{l}0.05 \\
(0.03 ; 0.02)\end{array}$ & $\begin{array}{l}0.10 \\
(0.09 ; 0.01)\end{array}$ \\
\hline
\end{tabular}

表3 神农架自然保护区内外1990-2010年各碳库碳密度(t C/ha)

Table 3 Carbon density ( $\mathrm{C} / \mathrm{ha}$ ) of different carbon pools inside and outside Shennongjia National Nature Reserve between 1990 and 2010

\begin{tabular}{|c|c|c|c|c|c|c|c|c|c|c|c|c|}
\hline & \multicolumn{2}{|c|}{$\begin{array}{l}\text { 地上碳库 } \\
\text { Aboveground carbon }\end{array}$} & \multicolumn{2}{|c|}{$\begin{array}{l}\text { 地下碳库 } \\
\text { Belowground } \\
\text { carbon }\end{array}$} & \multicolumn{2}{|c|}{$\begin{array}{l}\text { 凋落物碳库 } \\
\text { Litter carbon }\end{array}$} & \multicolumn{2}{|c|}{$\begin{array}{l}\text { 粗木质残体碳库 } \\
\text { Coarse woody } \\
\text { debris carbon }\end{array}$} & \multicolumn{2}{|c|}{$\begin{array}{l}\text { 土壤有机碳库 } \\
\text { Soil organic } \\
\text { carbon }\end{array}$} & \multicolumn{2}{|l|}{$\begin{array}{l}\text { 总计 } \\
\text { Total }\end{array}$} \\
\hline & $\begin{array}{l}\text { 内 } \\
\text { Inside }\end{array}$ & $\begin{array}{l}\text { 外 } \\
\text { Outside }\end{array}$ & $\begin{array}{l}\text { 内 } \\
\text { Inside }\end{array}$ & $\begin{array}{l}\text { 外 } \\
\text { Outside }\end{array}$ & $\begin{array}{l}\text { 内 } \\
\text { Inside }\end{array}$ & $\begin{array}{l}\text { 外 } \\
\text { Outside }\end{array}$ & $\begin{array}{l}\text { 内 } \\
\text { Inside }\end{array}$ & $\begin{array}{l}\text { 外 } \\
\text { Outside }\end{array}$ & $\begin{array}{l}\text { 内 } \\
\text { Inside }\end{array}$ & $\begin{array}{l}\text { 外 } \\
\text { Outside }\end{array}$ & $\begin{array}{l}\text { 内 } \\
\text { Inside }\end{array}$ & $\begin{array}{l}\text { 外 } \\
\text { Outside }\end{array}$ \\
\hline 1990 & 117.76 & 121.10 & 24.77 & 25.42 & 3.92 & 4.00 & 2.22 & 2.51 & 184.21 & 157.04 & 332.87 & 310.08 \\
\hline 2000 & 117.95 & 121.63 & 24.81 & 25.53 & 3.93 & 4.02 & 2.22 & 2.52 & 184.26 & 157.20 & 333.17 & 310.90 \\
\hline 2010 & 117.96 & 121.60 & 24.81 & 25.53 & 3.92 & 4.02 & 2.22 & 2.51 & 184.30 & 157.19 & 333.22 & 310.85 \\
\hline $\begin{array}{l}\text { 1990-2010年增加量 } \\
\triangle C_{\text {dendity }} 1990-2010 \\
(1990-2000 ; 2000-2010)\end{array}$ & $\begin{array}{l}0.20 \\
(0.19 \\
0.01)\end{array}$ & $\begin{array}{l}0.50 \\
(0.52 \\
-0.02)\end{array}$ & $\begin{array}{l}0.04 \\
(0.04 \\
0)\end{array}$ & $\begin{array}{l}0.10 \\
(0.11 \\
-0.01)\end{array}$ & $\begin{array}{l}0 \\
(0.01 \\
0)\end{array}$ & $\begin{array}{l}0.02 \\
(0.02 \\
-0.01)\end{array}$ & $\begin{array}{l}0.01 \\
(0.01 ; 0)\end{array}$ & $\begin{array}{l}0.01 \\
(0.01 ; 0)\end{array}$ & $\begin{array}{l}0.09 \\
(0.05 \\
0.04)\end{array}$ & $\begin{array}{l}0.15 \\
(0.16 \\
-0.01)\end{array}$ & $\begin{array}{l}0.34 \\
(0.30 \\
0.04)\end{array}$ & $\begin{array}{l}0.77 \\
(0.82 \\
-0.05)\end{array}$ \\
\hline
\end{tabular}




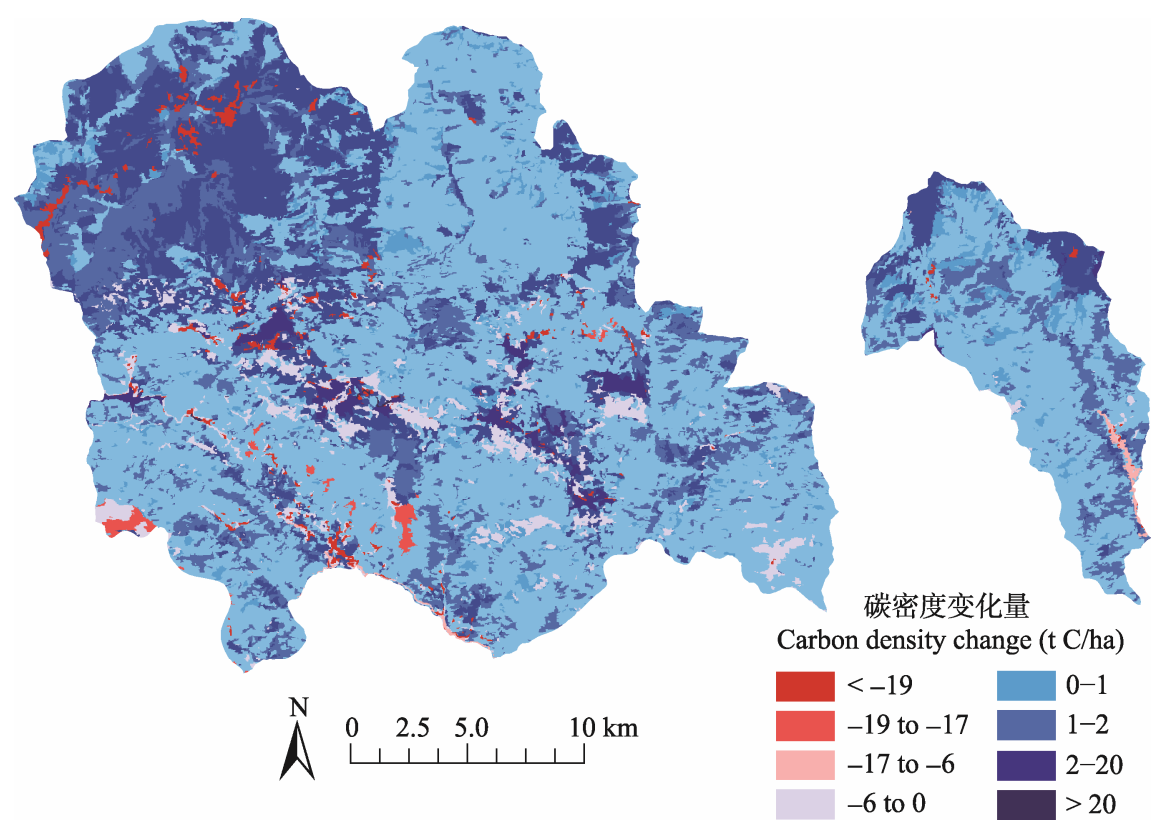

图2 神农架自然保护区1990-2010年碳密度变化量

Fig. 2 Carbon density change in Shennongjia National Nature Reserve between 1990 and 2010

本研究发现, 神农架保护区林地占保护区总面 积的 $92 \%$ 。神农架自 1970 年设置林区政府以来, 采 伐木材为林区主要生产任务, 森林覆盖率由开发前 的 $75.4 \%$ 下降至 $63.5 \%$, 林木蓄积量急剧下降(湖北 省神农架林区地方志编纂委员会, 1996)。神农架保 护区1982年建立后, 开始了由采伐向森林资源保护 的转变, 木材年产量调减 4.8 万 $\mathrm{m}^{3}$ (郑重等, 1997), 森林蓄积量每年增加 17 万 $\mathrm{m}^{3}$ (湖北省神农架林区地 方志编纂委员会, 1996)。保护区的建立有效缓解了 神农架保护区内森林的丧失(王翠玲等, 2017)。而同 期相比, 神农架保护区外森林砍伐严重, 直到国家 实施天然林保护工程和退耕还林工程后, 砍伐才全 面禁止。目前, 保护区内1990-2010年间碳储量变化 率为 $0.1 \%$, 较保护区外碳储量变化率低 $0.15 \%$, 主 要由于保护区外多为幼龄林, 恢复迅速, 优势种生 长迅速, 而保护区内多为中龄林或成熟林(郑重等, 1997)。保护区内土壤碳密度高于保护区外, 而土壤 碳为碳库组成的最主要部分, 因此保护区内总碳密 度高于保护区外。

本研究从地上、地下、调落物、粗木质残体、 土壤有机碳库 5 个方面估算了神农架保护区的固碳 有效性。地上碳估算通过胸径、树高、材积等指标, 利用生物量方程或异速生长模型估算生物量, 是区 域尺度上估算碳储量的常用方法(Chave et al, 2005;
Nogueira et al, 2008; Singh et al, 2011)。生物量方程 或异速生长模型主要针对优势物种碳储量的估算, 在估算碳储量时, 其结果往往有一定的不确定性 (Xiang et al, 2011; Willcock et al, 2012, 2016)。对地 上和地下生物量的估算结果, 采用重抽样方法生成 加权平均值的置信区间, 考虑了调查区域面积的不 确定性, 保证了各个碳库估算的可靠性(Willcock et $\mathrm{al}, 2012)$ 。另外, 调落物碳库、粗木质残体碳库实测 值较少, 但其在总碳储量中所占比重低(IPCC, 2006)。土壤有机碳采用的 SoilGrids $250 \mathrm{~m}$ (www.soilgrids.org)数据通过交叉验证保证了数据 的可靠性(Hengl et al, 2017)。

事实证明, 神农架保护区的建立, 在一定程度 上维持了森林生态系统的固碳能力, 取得了一定 的固碳保护成效。

\section{参考文献}

Andam KS, Ferraro PJ, Pfaff A, Sanchez-Azofeifa GA, Robalino JA (2008) Measuring the effectiveness of protected area networks in reducing deforestation. Proceedings of the National Academy of Sciences, USA, 105, 16089-16094.

Bowker JN, de Vos A, Ament JM, Cumming GS (2017) Effectiveness of Africa's tropical protected areas for maintaining forest cover. Conservation Biology, 31, 559-569.

Bruner AG, Gullison RE, Rice RE, da Fonseca GAB (2001) 
Effectiveness of parks in protecting tropical biodiversity. Science, 291, 125-128.

Cao MT, Peng L, Liu SQ (2015) Analysis of the network of protected areas in China based on a geographic perspective: Current status, issues and integration. Sustainability, 7, 15617-15631.

Carranza T, Balmford A, Kapos V, Manica A (2014) Protected area effectiveness in reducing conversion in a rapidly vanishing ecosystem: The Brazilian Cerrado. Conservation Letters, 7, 216-223.

Chave J, Andalo C, Brown S, Cairns MA, Chambers JQ, Eamus D, Fölster H, Fromard F, Higuchi N, Kira T, Lescure JP, Nelson BW, Ogawa H, Puig H, Riéra B, Yamakura T (2005) Tree allometry and improved estimation of carbon stocks and balance in tropical forests. Oecologia, 145, 87-99.

Chen QQ, Xu WQ, Li SG, Fu SL, Yan JH (2013) Aboveground biomass and corresponding carbon sequestration ability of four major forest types in south China. Chinese Science Bulletin, 58, 1551-1557.

Chen YH, Zhang J, Jiang JP, Nielsen SE, He FL (2017) Assessing the effectiveness of China's protected areas to conserve current and future amphibian diversity. Diversity and Distributions, 23, 146-157.

Cui HX, Xiao WF, Huang ZL, Zeng LX, Pan L, Pang HD (2014) Soil organic carbon storage of three coniferous forests in Shennongjia Nature Reserve. Journal of Northeast Forestry University, 42, 69-72. (in Chinese with English abstract) [崔鸿侠, 肖文发, 黄志霖, 曾立雄, 潘䂞, 庞宏东 (2014) 神农架3种针叶林土壤碳储量比较. 东北林业大 学学报, 42, 69-72.]

Cui HX, Xiao WF, Pan L, Huang ZL, Wang XR, Pang HD (2012) Characteristics of soil carbon storage of Abies fargesii forest in Shennongjia. Scientia Silvae Sinicae, 48, 107-111. (in Chinese with English abstract) [崔鸿侠, 肖文 发, 潘磊, 黄志霖, 王晓荣, 庞宏东 (2012) 神农架巴山 冷杉林土壤碳储量特征. 林业科学, 48, 107-111.]

Dixon RK, Solomon AM, Brown S, Houghton RA, Trexier MC, Wisniewski J (1994) Carbon pools and flux of global forest ecosystems. Science, 263, 185-190.

Editorial Committee of Hubei Shennongiia Forestry District Local Chronicles (1996) Shennongiia chronicles. Hubei Science and Technology Press, Wuhan. (in Chinese) [湖北 省神农架林区地方志编纂委员会 (1996) 神农架志. 湖 北科学技术出版社, 武汉.]

Fang JY, Chen AP, Peng CH, Zhao SQ, Ci LJ (2001) Changes in forest biomass carbon storage in China between 1949 and 1998. Science, 292, 2320-2322.

Foley JA, DeFries R, Asner GP, Barford C, Bonan G, Carpenter SR, Chapin FS, Coe MT, Daily GC, Gibbs HK, Helkowski JH, Holloway T, Howard EA, Kucharik CJ, Monfreda C, Patz JA, Prentice IC, Ramankutty N, Snyder PK (2005) Global consequences of land use. Science, 309,
570-574.

Gaston KJ, Jackson SF, Cantú-Salazar L, Cruz-Piñón G (2008) The ecological performance of protected areas. Annual Review of Ecology, Evolution, and Systematics, 39, 93-113.

Hengl T, de Jesus JM, Heuvelink GBM, Gonzalez MR, Kilibarda M, Blagotic A, Shangguan W, Wright MN, Geng XY, Bauer-Marschallinger B, Guevara MA, Vargas R, MacMillan RA, Batjes NH, Leenaars JGB, Ribeiro E, Wheeler I, Mantel S, Kempen B (2017) SoilGrids250m: Global gridded soil information based on machine learning. PLoS ONE, 12, e0169748.

Hill R, Miller C, Newell B, Dunlop M, Gordon IJ (2015) Why biodiversity declines as protected areas increase: The effect of the power of governance regimes on sustainable landscapes. Sustainability Science, 10, 357-369.

Houghton RA, House JI, Pongratz J, van der Werf GR, DeFries RS, Hansen MC, Le Quéré C, Ramankutty N (2012) Carbon emissions from land use and land-cover change. Biogeosciences Discussions, 9, 835-878.

IPCC (2006) 2006 IPCC guidelines for national greenhouse gas inventories. Institute for Global Environmental Strategies, Kanagawa, Japan.

Jenkins CN, van Houtan KS, Pimm SL, Sexton JO (2015) US protected lands mismatch biodiversity priorities. Proceedings of the National Academy of Sciences, USA, 122, 5081-5086.

Joppa LN, Loarie SR, Pimm SL (2008) On the protection of "protected areas". Proceedings of the National Academy of Sciences, USA, 105, 6673-6678.

Joppa LN, Pfaff A (2009) High and far: Biases in the location of protected areas. PLoS ONE, 4, e8273.

Juffe-Bignoli D, Burgess ND, Bingham H, Belle EMS, de Lima MG, Deguignet M, Bertzky B, Milam AN, Martinez-Lopez J, Lewis E, Eassom A, Wicander S, Geldmann J, van Soesbergen A, Arnell AP, O’Connor B, Park S, Shi YN, Danks FS, MacSharry B, Kingston N (2014) Protected Planet Report 2014. UNEP-WCMC, Cambridge, UK.

Lai L, Huang XJ, Yang H, Chuai XW, Zhang M, Zhong TY, Chen ZG, Chen Y, Wang X, Thompson JR (2016) Carbon emissions from land-use change and management in China between 1990 and 2010. Science Advances, 2, e1601063.

Lambin EF, Turner BL, Geist HJ, Agbola SB, Angelsen A, Bruce JW, Coomes OT, Dirzo R, Fischer G, Folke C, George PS, Homewood K, Imbernon J, Leemans R, Li XB, Moran EF, Mortimore M, Ramakrishnan PS, Richards JF, Skånes H, Steffen W, Stone GD, Svedin U, Veldkamp TA, Vogel C, Xu JC (2001) The causes of land-use and land-cover change: Moving beyond the myths. Global Environmental Change, 11, 261-269.

Luo YJ, Wang XK, Lu F (2015) Comprehensive Database of Biomass Regressions for China's Tree Species. China Forestry Publishing House, Beijing. (in Chinese) [罗云建, 王 效科, 逯非 (2015) 中国主要林木生物量模型手册. 中国 
林业出版社，北京.]

Ma MZ, Shen GZ, Xiong GM, Zhao CM, Xu WT, Zhou YB, Xie ZQ (2017) Characteristic and representativeness of the vertical vegetation zonation along the altitudinal gradient in Shennongjia Natural Heritage. Chinese Journal of Plant Ecology, 41, 1127-1139. (in Chinese with English abstract) [马明哲, 申国珍, 熊高明, 赵常明, 徐文婷, 周友兵, 谢 宗强 (2017) 神农架自然遗产地植被垂直带谱的特点和 代表性. 植物生态学报, 41, 1127-1139.]

Nogueira EM, Fearnside PM, Nelson BW, Barbosa RI, Keizer EWH (2008) Estimates of forest biomass in the Brazilian Amazon: New allometric equations and adjustments to biomass from wood-volume inventories. Forest Ecology and Management, 256, 1853-1867.

Ouyang ZY, Zheng H, Xiao Y, Polasky S, Liu JG, Xu WH, Wang Q, Zhang L, Xiao Y, Rao EM, Jiang L, Lu F, Wang XK, Yang GB, Gong SH, Wu BF, Zeng Y, Yang W, Daily GC (2016) Improvements in ecosystem services from investments in natural capital. Science, 352, 1455-1459.

Pouzols FM, Toivonen T, Minin ED, Kukkala A, Kullberg P, Kuusterä J, Lehtomäki J, Tenkanen H, Verburg PH, Moilanen A (2014) Global protected area expansion is compromised by projected land-use and parochialism. Nature, 516, 383-386.

Ren GP, Young SS, Wang L, Wang W, Long YC, Wu RD, Li JS, Zhu JG, Yu DW (2015) Effectiveness of China's national forest protection program and nature reserves. Conservation Biology, 29, 1368-1377.

Rodrigues ASL, Andelman SJ, Bakarr MI, Boitani L, Brooks TM, Cowling RM, Fishpool LDC, da Fonseca GAB, Gaston KJ, Hoffmann M, Long JS, Marquet PA, Pilgrim JD, Pressey RL, Schipper J, Sechrest W, Stuart SN, Underhill LG, Waller RW, Watts MEJ, Xie Y (2004) Effectiveness of the global protected area network in representing species diversity. Nature, 428, 637-640.

Scharlemann JPW, Kapos V, Campbell A, Lysenko I, Burgess ND, Hansen MC, Gibbs HK, Dickson B, Miles L (2010) Securing tropical forest carbon: The contribution of protected areas to REDD. Oryx, 44, 352-357.

Scherer L, Curran M, Alvarez M (2017) Expanding Kenya's protected areas under the convention on biological diversity to maximize coverage of plant diversity. Conservation Biology, 31, 302-310.

Schimel D, Melillo J, Tian HQ, McGuire AD, Kicklighter D, Kittel T, Rosenbloom N, Running S, Thornton P, Ojima D, Parton W, Kelly R, Sykes M, Neilson R, Rizzo B (2000) Contribution of increasing $\mathrm{CO}_{2}$ and climate to carbon storage by ecosystems in the United States. Science, 287, 2004-2006.

Schlesinger WH (1990) Evidence from chronosequence studies for a low carbon-storage potential of soils. Nature, 348, 232-234.

Singh V, Tewari A, Kushwaha SPS, Dadhwal VK (2011) For- mulating allometric equations for estimating biomass and carbon stock in small diameter trees. Forest Ecology and Management, 261, 1945-1949.

Tans PP, Fung IY, Takahashi T (1990) Observational constraints on the global atmospheric $\mathrm{CO}_{2}$ budget. Science, 247, 1431-1438.

Technical Manual Writing Group of Ecosystem Carbon Sequestration Project (2015) Observation and Investigation for Carbon Sequestration in Terrestrial Ecosystems. Science Press, Beijing. (in Chinese) [生态系统固碳项目技术规范 编写组 (2015) 生态系统固碳观测与调查技术规范. 科 学出版社, 北京.]

Thomas CD, Gillingham PK, Bradbury RB, Roy DB, Anderson BJ, Baxter JM, Bourn NAD, Crick HQP, Findon RA, Fox R, Hodgson JA, Holt AR, Morecroft MD, O'Hanlon NJ, Oliver TH, Pearce-Higgins JW, Procter DA, Thomas JA, Walker KJ, Walmsley CA, Wilson RJ, Hill JK (2012) Protected areas facilitate species' range expansions. Proceedings of the National Academy of Sciences, USA, 109, 14063-14068.

Wang CL, Zang ZH, Qiu Y, Deng SY, Feng ZY, Xie ZQ, Xu WT, Liu L, Chen QS, Shen GZ (2017) The effectiveness of Shennongjia National Nature Reserve in conserving forests and habitat of Sichuan snub-nosed monkey. Biodiversity Science, 25, 504-512. (in Chinese with English abstract) [王 翠玲, 藏振华, 邱月, 邓舒雨, 冯朝阳, 谢宗强, 徐文婷, 刘蕾, 陈全胜, 申国珍 (2017) 湖北神农架国家级自然保 护区森林和川金丝猴栖息地的保护成效. 生物多样性, 25, 504-512.]

Willcock S, Phillips OL, Platts PJ, Balmford A, Burgess ND, Lovett JC, Ahrends A, Bayliss J, Doggart N, Doody K, Fanning E, Green JMH, Hall J, Howell KL, Marchant R, Marshall AR, Mbilinyi B, Munishi PKT, Owen N, Swetnam RD, Topp-Jorgensen EJ, Lewis SL (2012) Towards regional, error-bounded landscape carbon storage estimates for data-deficient areas of the world. PLoS ONE, 7, e44795.

Willcock S, Phillips OL, Platts PJ, Swetnam RD, Balmford A, Burgess ND, Ahrends A, Bayliss J, Doggart N, Doody K, Fanning E, Green JMH, Hall J, Howell KL, Lovett JC, Marchant R, Marshall AR, Mbilinyi B, Munishi PKT, Owen N, Topp-Jorgensen EJ, Lewis SL (2016) Land cover change and carbon emissions over 100 years in an African biodiversity hotspot. Global Change Biology, 22, 2787-2800.

Wu BF, Yuan QZ, Yan CZ, Wang ZM, Yu XF, Li AN, Ma RH, Huang JL, Chen JS, Chang C, Liu CL, Zhang L, Li XS, Zeng Y, Bao AM (2014) Land cover changes of China from 2000 to 2010. Quaternary Sciences, 34, 723-731. (in Chinese with English abstract) [吴炳方, 苑全治, 颜长珍, 王 宗明, 于信芳, 李爱农, 马荣华, 黄进良, 陈劲松, 常存, 刘成林, 张磊, 李晓松, 曾源, 包安明 (2014) 21 世纪前 十年的中国土地覆盖变化. 第四纪研究, 34, 723-731.]

Wu RD, Zhang S, Yu DW, Zhao P, Li XH, Wang LZ, Yu Q, Ma J, Chen A, Long YC (2011) Effectiveness of China's nature reserves in representing ecological diversity. Frontiers 
in Ecology and the Environment, 9, 383-389.

Xiang WH, Liu SH, Deng XW, Shen AH, Lei XD, Tian DL, Zhao MF, Peng CH (2011) General allometric equations and biomass allocation of Pinus massoniana trees on a regional scale in southern China. Ecological Research, 26, 697-711.

Xie ZB, Zhu JG, Liu G, Cadisch G, Hasegawa T, Chen CM, Sun HF, Tang HY, Zeng Q (2007) Soil organic carbon stocks in China and changes from 1980s to 2000s. Global Change Biology, 13, 1989-2007.

Xie ZQ, Shen GZ, Zhou YB, Fan DY, Xu WT, Gao XM, Du YJ, Xiong GM, Zhao CM, Zhu Y, Lai JS (2017) The outstanding universal value and conservation of the Shennongjia World Natural Heritage Site. Biodiversity Science, 25, 490-497. (in Chinese with English abstract) [谢宗强, 申国 珍, 周友兵, 柇大勇, 徐文婷, 高贤明, 杜彦君, 熊高明, 赵常明，祝燕，赖江山 (2017) 神农架世界自然遗产地的 全球突出普遍价值及其保护. 生物多样性, 25, 490-497.]
Xu WH, Xiao Y, Zhang JJ, Yang W, Zhang L, Hull V, Wang Z, Zheng H, Liu JG, Polasky S, Jiang L, Xiao Y, Shi XW, Rao EM, Lu F, Wang XK, Daily GC, Ouyang ZY (2017) Strengthening protected areas for biodiversity and ecosystem services in China. Proceedings of the National Academy of Sciences, USA, 114, 1601-1606.

Zhang L, Wu BF, Li XS, Xing Q (2014) Classification system of China land cover for carbon budget. Acta Ecologica Sinica, 34, 7158-7166. (in Chinese with English abstract) [张磊, 吴炳方, 李晓松, 邢强 (2014) 基于碳收支的中国 土地覆被分类系统. 生态学报, 34, 7158-7166.]

Zheng Z, Zhan YH, Xie JL (1997) Shennongjia of China. Hubei Science and Technology Press, Wuhan. (in Chinese) [郑 重, 詹亚华, 谢继伦 (1997) 中国神农架. 湖北科学技术 出版社, 武汉.]

(责任编委: 唐志尧 责任编辑: 时意专)

\section{附录 Supplementary Material}

附录1 用于估算碳储量的地上生物量模型

Appendix 1 Aboveground biomass models used for estimating carbon storage

http://www.biodiversity-science.net/fileup/PDF/2017240-1.pdf

附录2 不同植被类型地上、地下生物量换算关系式

Appendix 2 The conversion between aboveground biomass and belowground biomass of different land cover types http://www.biodiversity-science.net/fileup/PDF/2017240-2.pdf

附录3 研究区域土地利用类型的凋落物碳库碳储量

Appendix 3 The carbon storage of litter carbon pool in different land use types in the study area http://www.biodiversity-science.net/fileup/PDF/2017240-3.pdf

\section{附录4 研究区域不同土地利用类型的粗木质残体碳库碳储量}

Appendix 4 The carbon storage of coarse woody debris carbon pool in different land use types in the study area http://www.biodiversity-science.net/fileup/PDF/2017240-4.pdf 
邓舒雨, 董向忠, 马明哲, 藏振华, 徐文婷, 赵常明, 谢宗强, 申国珍. 基于森林碳库动态评估神农架国家级自然保护区的保护成效. 生物多样性, 2018, 26(1): 27-35. http://www.biodiversity-science.net/CN/10.17520/biods.2017240

\section{附录1 用于估算碳储量的地上生物量模型}

Appendix 1 Aboveground biomass models used for estimating carbon storage

\begin{tabular}{|c|c|c|c|c|c|c|c|}
\hline 物种类型 & 研究范围 & 林分起源 & 来源 & 地上模型 & 相关系数 R & 决定系数 $\mathrm{R}^{2}$ & 样本量 n \\
\hline Species & Study area & Forest stand & Reference & Model & & & \\
\hline 云冷杉通用 & 全国 & - & - & $\mathrm{B}=0.2848 \mathrm{D}^{2.1344}$ & - & 0.962 & 55 \\
\hline \multicolumn{8}{|l|}{ Picea spp. } \\
\hline \multicolumn{8}{|l|}{ Abies spp. } \\
\hline 冷杉 & 吉林 & 天然林 & 陈传国等, 1984 & $\mathrm{~B}=0.0763 \mathrm{D}^{2.4578}$ & 0.9954 & - & 20 \\
\hline Abies fabri & & & 陈传国等, 1989 & & & & \\
\hline 油麦吊云杉 & 云南 & 天然林 & 吴兆录等, 1994 & $\mathrm{~B}=0.0561 \mathrm{D}^{2.4254}$ & 0.9898, 0.991, & - & - \\
\hline Picea brachytyla & & & & $+0.0125 \mathrm{D}^{2.306}$ & $0.948,0.9256$ & & \\
\hline \multirow[t]{2}{*}{ var. complanata } & & & & $+0.0106 \mathrm{D}^{2.4539}$ & & & \\
\hline & & & & $-5.9633+0.9984 \mathrm{D}$ & & & \\
\hline 油桐 & 湖南 & 人工林 & 何方等, 1990 & $\mathrm{~B}=0.0202 \mathrm{D}^{2.9265}$ & 0.9952, 0.9882 & - & 18 \\
\hline Vernicia fordii & & & & $-0.0052 \mathrm{D}^{2.6381}$ & & & \\
\hline 元宝槭 & 北京 & 人工林 & 阎海平等, 1997 & $\mathrm{~B}=0.0506\left(\mathrm{D}^{2} \mathrm{H}\right)^{0.8812}$ & 0.995, 0.962, & - & 8 \\
\hline \multirow[t]{3}{*}{ Acer truncatum } & & & 田奇凡等, 1997 & $+0.014\left(\mathrm{D}^{2} \mathrm{H}\right)^{0.8358}$ & $0.996,0.913$ & & \\
\hline & & & & $+0.0115\left(\mathrm{D}^{2} \mathrm{H}\right)^{0.9786}$ & & & \\
\hline & & & & $+0.0125\left(\mathrm{D}^{2} \mathrm{H}\right)^{0.6869}$ & & & \\
\hline 红华 & 陕西 & 天然林 & 陈存根等, 1996 & $\mathrm{~B}=\mathrm{e}^{-3.7933}\left(\mathrm{D}^{2} \mathrm{H}\right)^{0.9104}$ & 0.9972, & - & - \\
\hline Betula & & & & $+\mathrm{e}^{-4.2775}\left(\mathrm{D}^{2} \mathrm{H}\right)^{0.8102}$ & 0.9967, & & \\
\hline \multirow[t]{3}{*}{ albo-sinensis } & & & & $+\mathrm{e}^{-5.9351} \mathrm{D}^{3.3593}$ & 0.9858, & & \\
\hline & & & & $+e^{-5.5693} \mathrm{D}^{2.3901}$ & 0.9871, & & \\
\hline & & & & $+\mathrm{e}^{-12.1436} \mathrm{D}^{3.9339}$ & 0.9826 & & \\
\hline 亮叶桦 & 福建 & 天然林 & 宋丁全等, 2002 & $\mathrm{~B}=0.0283 \mathrm{D}^{2.4533} \mathrm{H}^{0.3455}$ & 0.9999, & - & 6 \\
\hline
\end{tabular}


邓舒雨, 董向忠, 马明哲, 藏振华, 徐文婷, 赵常明, 谢宗强, 申国珍. 基于森林碳库动态评估神农架国家级自然保护区的保护成效. 生物多样性, 2018, 26(1): 27-35. http://www.biodiversity-science.net/CN/10.17520/biods.2017240

\begin{tabular}{|c|c|c|c|c|c|c|c|}
\hline 物种类型 & 研究范围 & 林分起源 & 来源 & 地上模型 & 相关系数 R & 决定系数 $\mathrm{R}^{2}$ & 样本量 $\mathrm{n}$ \\
\hline Species & Study area & Forest stand & Reference & Model & & & \\
\hline \multirow[t]{3}{*}{ Betula luminifera } & & & & $+0.0189 \mathrm{D}^{1.9122} \mathrm{H}^{0.2508}$ & 0.996, & & \\
\hline & & & & $+0.0021 \mathrm{D}^{2.0737} \mathrm{H}^{1.2093}$ & 0.9881, & & \\
\hline & & & & $+0.1111 \mathrm{D}^{1.065} \mathrm{H}^{0.2048}$ & 0.9872 & & \\
\hline 阔叶树通用 & 全国 & - & - & $\mathrm{B}=0.0622 \mathrm{D}^{2.5289}$ & - & 0.933 & 1140 \\
\hline 杉木通用 & 全国 & - & - & $\mathrm{B}=0.0785 \mathrm{D}^{2.373}$ & - & 0.843 & 110 \\
\hline \multirow{2}{*}{\multicolumn{8}{|c|}{$\begin{array}{l}\text { Cunninghamia } \\
\text { lanceolata }\end{array}$}} \\
\hline & & & & & & & \\
\hline 柏木 & 贵州 & 次生林 & 安和平等, 1991 & $\mathrm{~B}=0.127\left(\mathrm{D}^{2} \mathrm{H}\right)^{0.7978}$ & 0.9884 & - & - \\
\hline \multirow{2}{*}{\multicolumn{8}{|c|}{$\begin{array}{l}\text { Cupressus } \\
\text { funebris }\end{array}$}} \\
\hline & & & & & & & \\
\hline 青冈 & 湖南 & 次生林 & Zheng et al., 2008 & $\mathrm{~B}=1.1963 \mathrm{D}^{1.4829}$ & - & 0.9833, 0.9425, 0.977, & 8 \\
\hline Cyclobalanopsis & & & & $-\left(0.2485 D^{0.8636}\right.$ & & 0.986 & \\
\hline \multirow[t]{2}{*}{ glauca } & & & & $+0.0369 \mathrm{D}^{1.0145}$ & & & \\
\hline & & & & $\left.+0.0092 \mathrm{D}^{1.0216}\right)$ & & & \\
\hline 米心水青冈 & 湖北 & 天然林 & 王向雨等, 2007 & $\mathrm{~B}=0.246 \mathrm{D}^{2.08}$ & 0.9908, & - & - \\
\hline \multirow[t]{2}{*}{ Fagus engleriana } & & & & $+0.0074 \mathrm{D}^{2.84}$ & 0.9913, & & \\
\hline & & & & $+0.00055 \mathrm{D}^{3.2}$ & 0.9989 & & \\
\hline 榕树 & 云南 & 次生林 & 冯志立等, 1999 & $\mathrm{~B}=0.0253\left(\mathrm{D}^{2} \mathrm{H}\right)^{0.9546}$ & 0.9988, & - & 8 \\
\hline \multirow[t]{2}{*}{ Ficus microcarpa } & & & & $+0.0013\left(\mathrm{D}^{2} \mathrm{H}\right)^{1.2487}$ & 0.9816, & & \\
\hline & & & & $+0.1179+0.001\left(\mathrm{D}^{2} \mathrm{H}\right)$ & 0.9786 & & \\
\hline 针叶树通用 & 全国 & - & - & $\mathrm{B}=0.1112 \mathrm{D}^{2.3689}$ & - & 0.926 & 900 \\
\hline 日本落叶松通用 & 全国 & - & - & $\mathrm{B}=172.329\left[(0.01 \mathrm{D})^{2} \mathrm{H}\right]^{1.1346}$ & - & 0.922 & 35 \\
\hline \multicolumn{8}{|l|}{ Larix kaempferi } \\
\hline 石栋 & 浙江 & 次生林 & 陈启瑺, 1993 & $\mathrm{~B}=-3.114+0.4371 \mathrm{D}^{2}$ & 0.9974 & - & 20 \\
\hline
\end{tabular}


邓舒雨, 董向忠, 马明哲, 藏振华, 徐文婷, 赵常明, 谢宗强, 申国珍. 基于森林碳库动态评估神农架国家级自然保护区的保护成效. 生物多样性, 2018, 26(1): 27-35. http://www.biodiversity-science.net/CN/10.17520/biods.2017240

\begin{tabular}{|c|c|c|c|c|c|c|c|}
\hline 物种类型 & 研究范围 & 林分起源 & 来源 & 地上模型 & 相关系数 R & 决定系数 $\mathrm{R}^{2}$ & 样本量 $\mathrm{n}$ \\
\hline Species & Study area & Forest stand & Reference & Model & & & \\
\hline \multicolumn{8}{|l|}{$\begin{array}{l}\text { Lithocarpus } \\
\text { glaber }\end{array}$} \\
\hline 木姜子 & 云南 & 次生林 & 冯志立等, 1999 & $\mathrm{~B}=0.1071+0.0254\left(\mathrm{D}^{2} \mathrm{H}\right)$ & 0.9401, & - & 7 \\
\hline Litsea pungens & & & & $\begin{array}{l}+0.0125\left(\mathrm{D}^{2} \mathrm{H}\right)^{0.9054} \\
+0.0000055\left(\mathrm{D}^{2} \mathrm{H}\right)^{1.666}\end{array}$ & $\begin{array}{l}0.9362 \\
0.9505\end{array}$ & & \\
\hline 檫木 & 福建 & 人工林 & 何贵平等, 2001 & $\mathrm{~B}=10^{-1.8346}\left(\mathrm{D}^{2} \mathrm{H}\right)^{1.0884}$ & 0.8841 & - & 8 \\
\hline Sassafras tzumu & & & & & & & \\
\hline 创花润楠 & 江西 & 天然林 & 钟全林等, 2001 & $\mathrm{~B}=2.71828^{-3.0557}\left(\mathrm{D}^{2} \mathrm{H}\right)^{0.9429}$ & 0.9517 & - & 37 \\
\hline Machilus pauhoi & & & & & & & \\
\hline 楠木 & 福建 & 人工林 & 廖涵宗等, 1988 & $\mathrm{~B}=10^{-1.0514}\left(\mathrm{D}^{2} \mathrm{H}\right)^{0.8541}$ & 0.9713 & - & 10 \\
\hline Phoebe zhennan & & & & & & & \\
\hline $\begin{array}{l}\text { 水杉通用 } \\
\text { Metasequoia } \\
\text { glyptostroboides }\end{array}$ & 全国 & - & - & $\mathrm{B}=143.256\left[(0.01 \mathrm{D})^{2} \mathrm{H}\right]^{0.7589}$ & - & 0.967 & 35 \\
\hline $\begin{array}{l}\text { 华山松 } \\
\text { Pinus armandii }\end{array}$ & 甘肃 & 人工林 & 程堂仁等, 2007 & $\begin{array}{r}\mathrm{B}=2.71828^{-2.2962} \mathrm{D}^{2.4119} \\
\quad-2.71828^{-6.1087} \mathrm{D}^{3.0376}\end{array}$ & $\begin{array}{l}0.998 \\
0.9886\end{array}$ & - & 86 \\
\hline $\begin{array}{l}\text { 巴山松 } \\
\text { Pinus henryi }\end{array}$ & 陕西 & 天然林 & 肖瑜, 1992 & $\begin{aligned} \mathrm{B}= & 0.0221\left(\mathrm{D}^{2} \mathrm{H}\right)^{0.9469} \\
& +0.0041\left(\mathrm{D}^{2} \mathrm{H}\right)^{0.943} \\
& +0.014 \mathrm{D}^{2.454} \\
& +0.0173 \mathrm{D}^{2.3207}\end{aligned}$ & $\begin{array}{l}0.996 \\
0.988, \\
0.98 \\
0.956\end{array}$ & - & 78 \\
\hline $\begin{array}{l}\text { 马尾松通用 } \\
\text { Pinus massoniana }\end{array}$ & 全国 & - & - & $\mathrm{B}=0.107 \mathrm{D}^{2.3755}$ & - & 0.954 & 100 \\
\hline $\begin{array}{l}\text { 山杨 } \\
\text { Populus }\end{array}$ & 吉林 & 天然林 & $\begin{array}{l}\text { 陈传国等, 1984; } \\
\text { 陈传国等, } 1989\end{array}$ & $\mathrm{~B}=0.5046 \mathrm{D}^{1.9615}$ & 0.9534 & - & 12 \\
\hline
\end{tabular}


邓舒雨, 董向忠, 马明哲, 藏振华, 徐文婷, 赵常明, 谢宗强, 申国珍. 基于森林碳库动态评估神农架国家级自然保护区的保护成效. 生物多样性, 2018, 26(1): 27-35. http://www.biodiversity-science.net/CN/10.17520/biods.2017240

\begin{tabular}{|c|c|c|c|c|c|c|c|}
\hline 物种类型 & 研究范围 & 林分起源 & 来源 & 地上模型 & 相关系数 R & 决定系数 $\mathrm{R}^{2}$ & 样本量 $\mathrm{n}$ \\
\hline Species & Study area & Forest stand & Reference & Model & & & \\
\hline \multicolumn{8}{|l|}{ davidiana } \\
\hline 锐齿葪栎 & 湖北 & 天然林 & 王向雨等, 2007 & $\mathrm{~B}=0.029 \mathrm{D}^{2.74}$ & 0.9961, & - & - \\
\hline Quercus aliena & & & & $+0.036 \mathrm{D}^{2.35}$ & 0.9813, & & \\
\hline var. acutiserrata & & & & $+0.0088 \mathrm{D}^{2.44}$ & 0.9756 & & \\
\hline 栓皮柇 & 甘肃 & 人工林 & 程堂仁等, 2007 & $\mathrm{~B}=\mathrm{e}^{-1.2141} \mathrm{D}^{2.1159}$ & 0.9863, & - & 87 \\
\hline Quercus variabilis & & & & $-\mathrm{e}^{-2.347} \mathrm{D}^{2.1003}$ & 0.9933 & & \\
\hline 杜鹃 & 云南 & 天然林 & 吴兆录等, 1994 & $\mathrm{~B}=11.3267 * 0.0023^{(1 / \mathrm{D})}$ & 0.9892 & - & - \\
\hline Rhododendron & & & & $+2.3486 * 0.0014^{(1 / \mathrm{D})}$ & 0.8439 & & \\
\hline simsii & & & & $+0.8559 * 0.0107^{(1 / \mathrm{D})}$ & 0.8113 & & \\
\hline 山矾 & 湖南 & 人工林 & 高述超等, 2010 & $\mathrm{~B}=0.0975\left(\mathrm{D}^{2} \mathrm{H}\right)^{0.8083}$ & - & 0.9863 & 6 \\
\hline Symplocos & & & & $+0.0236\left(\mathrm{D}^{2} \mathrm{H}\right)^{0.6793}$ & & 0.9898, & \\
\hline \multirow[t]{2}{*}{ sumuntia } & & & & $+0.0631\left(D^{2} \mathrm{H}\right)^{0.8124}$ & & 0.9851 & \\
\hline & & & & $+0.23\left(\mathrm{D}^{2} \mathrm{H}\right)^{0.452}$ & & 0.9192 & \\
\hline 狭叶珍珠花 & 云南 & 天然林 & 党承林等, 1994 & $B=2.6894-5.2195 / D$ & 0.9645 & - & 28 \\
\hline Lyonia ovalifolia & & & & $+0.8309-1.4361 / \mathrm{D}$ & 0.965, & & \\
\hline var. lanceolate & & & & $-0.0363+0.0126 \mathrm{D}^{2}$ & 0.9287 & & \\
\hline 桦类通用 & 全国 & - & - & $\mathrm{B}=0.6352 \mathrm{D}^{1.9296}$ & - & 0.912 & 90 \\
\hline \multicolumn{8}{|l|}{ Betulaceae spp. } \\
\hline 白栋 & 湖南 & 人工林 & 欧阳硕龙等, 2010 & $\mathrm{~B}=0.0263\left(\mathrm{D}^{2} \mathrm{H}\right)^{0.9174}$ & 0.9978 & - & 70 \\
\hline \multirow[t]{3}{*}{ Quercus fabri } & & & & $+0.0081\left(D^{2} \mathrm{H}\right)^{0.8915}$ & 0.9948, & & \\
\hline & & & & $+0.0811\left(\mathrm{D}^{2} \mathrm{H}\right)^{0.6404}$ & 0.9909, & & \\
\hline & & & & $+0.0153\left(\mathrm{D}^{2} \mathrm{H}\right)^{0.7501}$ & 0.9836 & & \\
\hline 落叶栎类通用 & 全国 & - & - & $\mathrm{B}=0.0664 \mathrm{D}^{2.5907}$ & - & 0.967 & 65 \\
\hline 臭椿 & 广西 & 人工林 & 杨主泉, 2013 & $\mathrm{~B}=0.876+0.0124\left(\mathrm{D}^{2} \mathrm{H}\right)$ & 0.811, & - & - \\
\hline
\end{tabular}


邓舒雨, 董向忠, 马明哲, 藏振华, 徐文婷, 赵常明, 谢宗强, 申国珍. 基于森林碳库动态评估神农架国家级自然保护区的保护成效. 生物多样性, 2018, 26(1): 27-35. http://www.biodiversity-science.net/CN/10.17520/biods.2017240

\begin{tabular}{|c|c|c|c|c|c|c|c|}
\hline 物种类型 & 研究范围 & 林分起源 & 来源 & 地上模型 & 相关系数 R & 决定系数 $\mathrm{R}^{2}$ & 样本量 n \\
\hline Species & Study area & Forest stand & Reference & Model & & & \\
\hline $\begin{array}{l}\text { Ailanthus } \\
\text { altissima }\end{array}$ & & & & $-\left[0.118+0.001\left(\mathrm{D}^{2} \mathrm{H}\right)\right]$ & 0.945 & & \\
\hline $\begin{array}{l}\text { 枫香树 } \\
\text { Liquidambar } \\
\text { formosan }\end{array}$ & 湖南 & 人工林 & 欧阳硕龙等, 2010 & $\begin{aligned} \mathrm{B}= & 0.0252\left(\mathrm{D}^{2} \mathrm{H}\right)^{0.9614} \\
& +0.005\left(\mathrm{D}^{2} \mathrm{H}\right)^{0.9553} \\
& +0.0053\left(\mathrm{D}^{2} \mathrm{H}\right)^{1.0132} \\
& +0.0072\left(\mathrm{D}^{2} \mathrm{H}\right)^{0.8658}\end{aligned}$ & $\begin{array}{l}0.9956 \\
0.9934 \\
0.9916 \\
0.9618\end{array}$ & - & 120 \\
\hline $\begin{array}{l}\text { 连香树 } \\
\text { Cercidiphyllum } \\
\text { japonicum }\end{array}$ & 四川 & 人工林 & 潘开文等, 1999 & $\mathrm{~B}=0.7199 \mathrm{D}^{1.5455}$ & 0.9924 & - & 15 \\
\hline $\begin{array}{l}\text { 山桐子 } \\
\text { Idesia polycarpa }\end{array}$ & 贵州 & 天然林 & 赵家梅等, 2012 & $\mathrm{~B}=0.2678 \mathrm{D}^{1.8682}$ & - & 0.9969 & 5 \\
\hline $\begin{array}{l}\text { 猴樟 } \\
\text { Cinnamomum } \\
\text { bodinieri }\end{array}$ & 云南 & 人工林 & 萧自位等, 2012 & $\begin{array}{c}\mathrm{B}=0.2191 \mathrm{D}^{1.9916} \\
\quad-0.045 \mathrm{D}^{1.9674}\end{array}$ & $\begin{array}{l}0.981 \\
0.973\end{array}$ & - & 12 \\
\hline $\begin{array}{l}\text { 杨树通用 } \\
\text { Populus spp. }\end{array}$ & 全国 & - & - & $\mathrm{B}=0.2498 \mathrm{D}^{2.1331}$ & - & 0.973 & 175 \\
\hline $\begin{array}{l}\text { 毛白杨 } \\
\text { Populus } \\
\text { tomentosa }\end{array}$ & 河南 & 人工林 & 刘元本等, 1984 & $\begin{array}{r}\mathrm{B}=0.0895 \mathrm{D}^{2.5453} \\
\quad-0.0148 \mathrm{D}^{2.4465}\end{array}$ & $\begin{array}{l}0.9975 \\
0.9857\end{array}$ & - & 13 \\
\hline $\begin{array}{l}\text { 榆树 } \\
\text { Ulmus pumila }\end{array}$ & 内蒙古 & 天然林 & 李刚等, 2011 & $\begin{aligned} \mathrm{B}= & \mathrm{e}^{-4.221} \mathrm{D}^{2.588} \\
& +\mathrm{e}^{-3.456} \mathrm{D}^{2.32} \\
& +\mathrm{e}^{-3.532} \mathrm{D}^{1.76}\end{aligned}$ & - & $\begin{array}{l}0.978, \\
0.985, \\
0.96\end{array}$ & 10 \\
\hline $\begin{array}{l}\text { 樟树通用 } \\
\text { Cinnamomum spp. }\end{array}$ & 全国 & - & 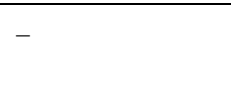 & $\mathrm{B}=315.81\left[(0.01 \mathrm{D})^{2} \mathrm{H}\right]^{1.1846}$ & - & 0.985 & 30 \\
\hline
\end{tabular}


邓舒雨, 董向忠, 马明哲, 藏振华, 徐文婷, 赵常明, 谢宗强, 申国珍. 基于森林碳库动态评估神农架国家级自然保护区的 保护成效. 生物多样性, 2018, 26(1): 27-35.

http://www.biodiversity-science.net/CN/10.17520/biods.2017240

附录 2 不同植被类型地上、地下生物量换算关系式。 $\mathrm{W}$ 表示地下生物量 $/ \mathrm{kg}$; B 表示地上生物量 $/ \mathrm{kg}$ 。

Appendix 2 The conversion between aboveground biomass and belowground biomass of different land cover types

\begin{tabular}{|c|c|c|}
\hline 类型 & 地上地下关系式 & 决定系数 \\
\hline Forest type & $\begin{array}{l}\text { Conversion between aboveground } \\
\text { biomass and belowground biomass }\end{array}$ & $\begin{array}{l}\text { Determination } \\
\text { coefficient }\end{array}$ \\
\hline 所有森林 & $\mathrm{W}=10^{-0.37} \mathrm{~B}^{0.859}$ & 0.762 \\
\hline 云杉属、冷杉属、圆柏属 & $\mathrm{W}=10^{-0.549} \mathrm{~B}^{0.945}$ & 0.613 \\
\hline 杉木 & $\mathrm{W}=10^{-0.294} \mathrm{~B}^{0.798}$ & 0.819 \\
\hline 柏木属、福建柏属 & $\mathrm{W}=10^{-0.79} \mathrm{~B}^{1.047}$ & 0.892 \\
\hline 落叶松属 & $\mathrm{W}=10^{-0.16} \mathrm{~B}^{0.763}$ & 0.599 \\
\hline 红松 & $\mathrm{W}=10^{-0.644} \mathrm{~B}^{0.993}$ & 0.857 \\
\hline 马尾松、黄山松 & $\mathrm{W}=10^{-0.338} \mathrm{~B}^{0.779}$ & 0.735 \\
\hline 油松 & $\mathrm{W}=10^{-0.307} \mathrm{~B}^{0.811}$ & 0.693 \\
\hline 其他温带松柏类 & $\mathrm{W}=10^{-0.251} \mathrm{~B}^{0.793}$ & 0.485 \\
\hline 其他亚热带松柏类 & $\mathrm{W}=10^{-0.745} \mathrm{~B}^{1.024}$ & 0.847 \\
\hline 桤木属、桦木属、杨属 & $\mathrm{W}=10^{-0.366} \mathrm{~B}^{0.887}$ & 0.841 \\
\hline 栎属、其他温带落叶阔叶林 & $\mathrm{W}=10^{-0.266} \mathrm{~B}^{0.877}$ & 0.742 \\
\hline 其他亚热带落叶阔叶林 & $\mathrm{W}=10^{-0.283} \mathrm{~B}^{0.802}$ & 0.802 \\
\hline 苦槠、青冈栋属、石栎属 & $\mathrm{W}=10^{-0.365} \mathrm{~B}^{0.902}$ & 0.802 \\
\hline 其他常绿阔叶林 & $\mathrm{W}=10^{-0.177} \mathrm{~B}^{0.8}$ & 0.793 \\
\hline 热带森林 & $\mathrm{W}=10^{-0.531} \mathrm{~B}^{0.949}$ & 0.816 \\
\hline 温带针阔混交林 & $\mathrm{W}=10^{-0.728} \mathrm{~B}^{1.024}$ & 0.84 \\
\hline 亚热带常绿阔叶林 & $\mathrm{W}=10^{-0.691} \mathrm{~B}^{1.001}$ & 0.78 \\
\hline 针叶林 & $\mathrm{W}=10^{-0.332} \mathrm{~B}^{0.82}$ & 0.765 \\
\hline 阔叶林 & $\mathrm{W}=10^{-0.275} \mathrm{~B}^{0.875}$ & 0.826 \\
\hline 针阔叶混交林 & $\mathrm{W}=10^{-0.711} \mathrm{~B}^{1.012}$ & 0.822 \\
\hline 落叶林 & $\mathrm{W}=10^{-0.253} \mathrm{~B}^{0.837}$ & 0.729 \\
\hline 常绿林 & $\mathrm{W}=10^{-0.415} \mathrm{~B}^{0.87}$ & 0.792 \\
\hline
\end{tabular}


邓舒雨, 董向忠, 马明哲, 藏振华, 徐文婷, 赵常明, 谢宗强, 申国珍. 基于森林碳库动态评估神农架国家级自然保护区的 保护成效. 生物多样性, 2018, 26(1): 27-35.

http://www.biodiversity-science.net/CN/10.17520/biods.2017240

附录3 研究区域土地利用类型的调落物碳库碳储量

Appendix 3 The carbon storage of litter carbon pool in different land use types in the study area

\begin{tabular}{lllll}
\hline $\begin{array}{l}\text { 类型 } \\
\text { Forest type }\end{array}$ & $\begin{array}{l}\text { 研究范围 } \\
\text { Study area }\end{array}$ & $\begin{array}{l}\text { 来源 } \\
\text { Reference }\end{array}$ & $\begin{array}{l}\text { 生物量碳密度 } \\
\text { Carbon storage per } \\
\text { hectare(t C/ha) }\end{array}$ & $\begin{array}{l}\text { 生物量密度 } \\
\text { Biomass per } \\
\text { hectare(t/ha) }\end{array}$ \\
\hline 针阔混交林 & & - & 6.32 \\
落叶阔叶林 & 三峡库区 & 曾立雄, 2007 & - & 8.51 \\
常绿阔叶林 & 三峡库区 & 曾立雄, 2007 & - & 10.18 \\
灌木林 & 三峡库区 & 曾立雄, 2007 & - & 7.51 \\
草地 & 三峡库区 & 曾立雄, 2007 & - & 0.49 \\
草甸 & 宁夏 & 刘延惠, 2011 & - & 0.82 \\
亚热带常绿针叶树 & 宁夏 & 刘延惠, 2011 & - & - \\
\hline
\end{tabular}


邓舒雨, 董向忠, 马明哲, 藏振华, 徐文婷, 赵常明, 谢宗强, 申国珍. 基于森林碳库动态评估神农架国家级自然保护区的 保护成效. 生物多样性, 2018, 26(1): 27-35.

http://www.biodiversity-science.net/CN/10.17520/biods.2017240

附录4 研究区域不同土地利用类型的粗木质残体碳库碳储量

Appendix 4 The carbon storage of coarse woody debris carbon pool in different land use types in the study area

\begin{tabular}{|c|c|c|c|c|}
\hline 类型 & 研究范围 & 来源 & 生物量碳密度 & 生物量密度 \\
\hline \multirow[t]{2}{*}{ Forest type } & Study area & Reference & Carbon storage per & Biomass per \\
\hline & & & hectare(t C/ha) & hectare(t/ha) \\
\hline 松榈混交林 & 江西 & 吴春生, 2016 & $0.521 \pm 0.08$ & $1.248 \pm 0.33$ \\
\hline 常绿阔叶林 & 江西 & 吴春生, 2016 & $4.781 \pm 0.37$ & $11.293 \pm 1.23$ \\
\hline \multirow[t]{2}{*}{ 针叶林 } & 广东鼎湖山 & 吕琨珑, 2013 & 0.09 & - \\
\hline & & 唐旭利, 2005 & & \\
\hline 锐齿葪栋林 & 秦岭 & 张洋, 2012 & 5.58 & - \\
\hline
\end{tabular}

